\title{
Erratum to: Analysis of pediatric airway morphology using statistical shape modeling
}

\author{
Stephen M. Humphries ${ }^{1,2} \cdot$ Kendall S. Hunter $^{2} \cdot$ Robin Shandas $^{2}$. \\ Robin R. Deterding ${ }^{3,4} \cdot$ Emily M. DeBoer ${ }^{3,4}$
}

Published online: 27 January 2016

(C) International Federation for Medical and Biological Engineering 2016

\section{Erratum to: Med Biol Eng Comput \\ DOI 10.1007/s11517-015-1445-x}

In the original publication of the article, Fig. 2 was published incorrectly. The correct version of Fig. 2 is given below and the original article has been updated accordingly.

The online version of the original article can be found under doi:10.1007/s11517-015-1445-x.

Stephen M. Humphries

Humphriess@NJHealth.org

1 Quantitative Imaging Laboratory, Department of Radiology,

National Jewish Health, 1400 Jackson St, Denver, CO

80206-2761, USA

2 Department of Bioengineering, University of Colorado Denver, 12705 E. Montview Ave., Aurora, CO 80045-7109, USA

3 Department of Pediatrics, University of Colorado Denver, Aurora, CO, USA

4 Children's Hospital Colorado, 13123 East 16th Avenue, Aurora, CO 80045, USA

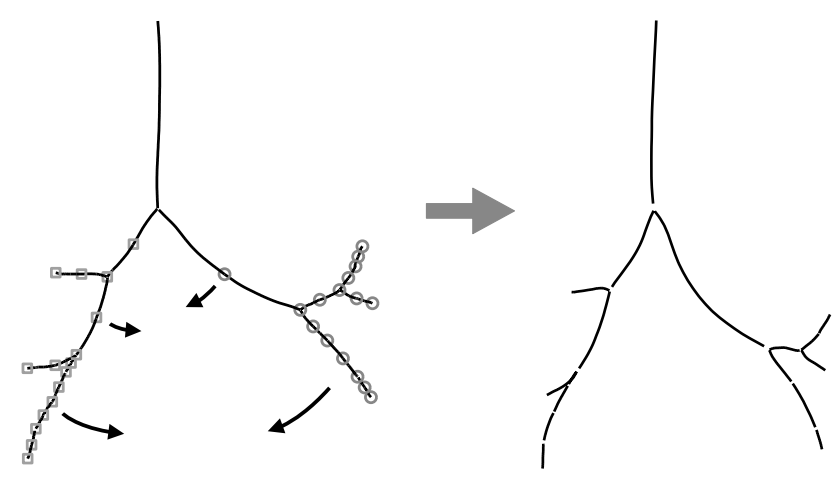

Fig. 2 Synthetic tree shapes for simulation experiments. The average tree shape was used as a basis and deformed using thin plate spline transforms. Bifurcations and branch midpoints were used as control points. Control points were independently rotated about the carina to displace them 